\title{
Effect of Sb as a surfactant during the lateral epitaxial overgrowth of GaN by metalorganic vapor phase epitaxy
}

\author{
L. Zhang, H. F. Tang, and T. F. Kuech ${ }^{\text {a) }}$ \\ Department of Chemical Engineering, University of Wisconsin-Madison, Madison, Wisconsin 53706
}

(Received 23 July 2001; accepted for publication 13 September 2001)

\begin{abstract}
Antimony ( $\mathrm{Sb}$ ), an isoelectronic impurity, has been studied as a surfactant during the lateral epitaxial overgrowth (LEO) of gallium nitride $(\mathrm{GaN})$ by metalorganic vapor phase epitaxy (MOVPE). The presence of $\mathrm{Sb}$ in the gas phase was found to alter both the LEO growth rates and the predominant facet formations. Vertical facets to the LEO growth appear with the addition of Sb under conditions that normally produce triangular or sloped sidewalls over a range of growth temperatures. While Sb alters the growth facets, only a small amount of $\mathrm{Sb}$ was incorporated into the GaN, suggesting that $\mathrm{Sb}$ acts as a surfactant during the GaN MOVPE growth. Sb addition produces surface conditions characteristic of a Ga-rich surface stoichiometry indicating both a possible change in the reactivity of $\mathrm{NH}_{3}$ and/or enhanced surface diffusion of Ga adatom species. (C) 2001 American Institute of Physics. [DOI: 10.1063/1.1415774]
\end{abstract}

The use of a suitable impurity, as a surfactant, during the growth of semiconductor films has attracted increasing interest in recent years. ${ }^{1-6}$ Elemental surfactants are typically characterized by low vapor pressure and low solubility in the solid. They can segregate to the surface and affect surface properties, such as the surface energy, reconstruction and surface kinetic processes of the growing surface. As a result, a small amount of surfactant impurities can significantly alter the growth characteristics and change the resulting film structure without a high level of incorporation into the films. For example, in the case of SiGe growth, antimony $(\mathrm{Sb})$ has been known to both segregate to the growth front and alter the surface energy of the SiGe. This change in surface energy results in an increase in the epitaxial thickness of the SiGe layer and facilitates layer by layer growth with respect to island growth. ${ }^{1,2}$ In this letter, we describe the use of the $\mathrm{Sb}$ isoelectronic center as a surfactant during the lateral epitaxial overgrowth (LEO) of gallium nitride $(\mathrm{GaN})$ by metalorganic vapor phase epitaxy (MOVPE).

$\mathrm{GaN}$ and related materials have been extensively investigated for applications to short wavelength optoelectronics and high temperature and high power electronics. One of the main issues in the GaN crystal growth is the reduction in the threading dislocation density arising from the large lattice mismatch between the GaN film and underlying substrate. The LEO growth technique has been reported as a route for achieving $\mathrm{GaN}$ with a significant reduction in the dislocation density. Long-lifetime GaN laser diodes fabricated on LEOgrown materials have been demonstrated. ${ }^{7}$ In these applications, it is desirable to increase the yield of the high quality $\mathrm{GaN}$ materials in the lateral overgrowth region. A high lateral overgrowth rate, as well as vertical facets, is typically chosen for smooth and rapid coalescence. ${ }^{8}$ The growth and structure of LEO GaN materials have been studied through control of many growth parameters, such as the growth temperature, ${ }^{9}$ mask orientation, ${ }^{10,11} \mathrm{~V} / \mathrm{III}$ ratio, ${ }^{12}$ mask fill factors, ${ }^{12}$ and

${ }^{a) E l e c t r o n i c ~ m a i l: ~ k u e c h @ e n g r . w i s c . e d u ~}$ with $\mathrm{Mg}$ and Si doping. ${ }^{13}$ In this work, a small amount addition of $\mathrm{Sb}$ was found to increase the lateral overgrowth rate and result in vertical facets under conditions that normally produce triangular or sloped sidewalls over a range of growth temperatures.

GaN:Sb LEO growth was carried out in a horizontal reactor operated at 76 Torr. Trimethylgallium (TMGa), triethylantimony (TESb), along with ammonia $\left(\mathrm{NH}_{3}\right)$, were used as precursors in Pd-diffused hydrogen carrier gas. The sample was heated in $\mathrm{NH}_{3}$ ambient before growth. As soon as the substrate reached the growth temperature, TMGa and TESb precursors were introduced into the reactor. The TMGa mole fraction within the reactor was $\sim 10^{-4}$. The gas phase $\mathrm{Sb}$ concentration was varied from a Sb/Ga mole ratio of $1.5 \%$ to $3 \%$ and $6 \%$. The growth temperature was controlled over the range of $1000-1100{ }^{\circ} \mathrm{C}$. The gas phase V/III ratio was kept at $\sim 5000$. The substrate was a $1.2 \mu \mathrm{m}$ MOVPE GaN epilayer on a $c$-plane sapphire substrate. $\operatorname{SiN}_{x}$ films were used as the masking layer. Patterning of the masks was performed using conventional photolithography and wet etching. A parallel stripe pattern was aligned in the $\langle 1 \overline{1} 00\rangle \mathrm{GaN}$ direction with a window opening width of $\sim 1 \mu \mathrm{m}$ and $\sim 10 \mu \mathrm{m}$ spacing. Scanning electron microscopy (SEM) was used to determine the morphology of LEO stripes. A secondary ion mass spectroscopy (SIMS) depth profile measurement was used to determine the $\mathrm{Sb}$ solid concentration on a nonpatterned substrate.

Figures 1(a)-(d) show the cross-sectional SEM images of undoped and Sb-doped LEO stripes grown under $1025^{\circ} \mathrm{C}$. For undoped growth, a triangular cross section was obtained for the LEO GaN shown in Fig. 1(a). These sloped facets were typically observed at relatively low growth temperatures. They mainly consisted of slow growth planes of $\{1 \overline{1} 01\}$. The sidewall of the LEO stripes was uneven and had zigzag-like features. A significant change in growth rates and facet formation was observed when $\mathrm{Sb}$ was added to the gas phase. An increase in the lateral overgrowth rate and a decrease in vertical growth rate were seen upon increasing the $\mathrm{Sb} / \mathrm{Ga}$ gas mole ratios from $1.5 \%$ to $3 \%$ and $6 \%$, as 

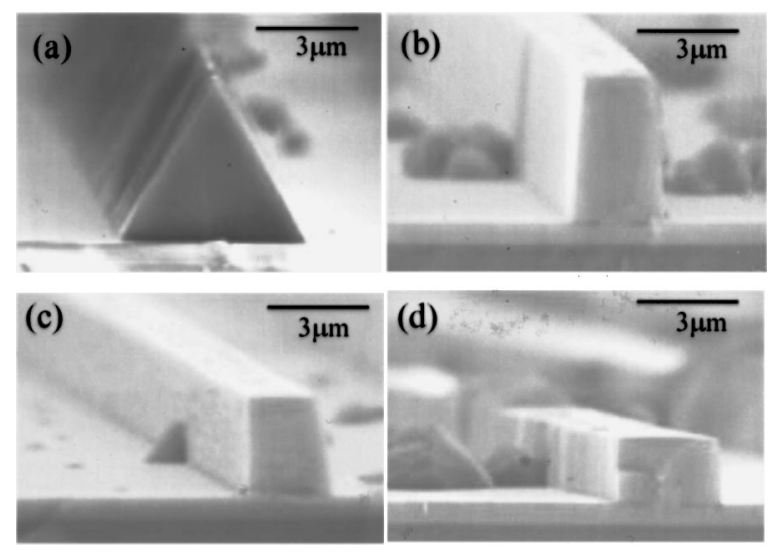

FIG. 1. Cross-sectional SEM images of undoped (a) and Sb-doped LEO islands grown at $1025^{\circ} \mathrm{C}$. The $\mathrm{Sb} / \mathrm{Ga}$ mole ratios are $1.5 \%$ (b), $3 \%$ (c), and $6 \%$ (d) in the gas phase.

shown in Figs. 1(b)-1(d). It can be clearly seen that the cross-sectional profile gradually changed from a triangular to a trapezoidal shape, and then finally to a rectangular shape. The vertical facets were identified as $\{11 \overline{2} 0\}$ planes. The sidewalls became smooth in these Sb-doped LEO stripes.

The effect of $\mathrm{Sb}$ addition to the LEO growth environment was further studied at higher growth temperatures. Figure 2 shows cross-sectional SEM images of undoped and $\mathrm{Sb}$-doped LEO stripes grown at $1075^{\circ} \mathrm{C}$. For undoped growth, the lateral overgrowth rate at an elevated growth temperature was greatly enhanced as shown in Fig. 2(a) compared to the growth at $1025^{\circ} \mathrm{C}$. The sidewall facets were smooth, but still sloped, and identified as $\{11 \overline{2} 2\}$ planes. With the addition of the Sb impurity to the gas phase, the sloped sidewall again converted to vertical facets $\{11 \overline{2} 0\}$ as shown in Fig. 2(b). This sample was grown under a $\mathrm{Sb} / \mathrm{Ga}$ gas phase mole ratio of $\sim 6 \%$.

While $\mathrm{Sb}$ addition greatly altered the appearance of specific growth facets, only a small amount of $\mathrm{Sb}$ was found to incorporate into the $\mathrm{GaN}$ thin films even grown at a high $\mathrm{Sb} / \mathrm{Ga}$ gas phase ratio as indicated by SIMS. For a sample grown at a high $\mathrm{Sb} / \mathrm{Ga}$ mole ratio of $12 \%$, the $\mathrm{Sb}$ solid concentration was determined to be $\sim 2 \times 10^{16} \mathrm{~cm}^{-3}$ in a GaN epilayer grown by conventional "two-step" growth on a sapphire substrate. This result suggests that the distribution coefficient of the $\mathrm{Sb}$ impurity within the $\mathrm{GaN}$, defined as the ratio of the $\mathrm{Sb} / \mathrm{Ga}$ mole ratio in the solid to that in the gas phase, was estimated to be around $10^{-6}$. The low incorporation rate is due to the low solid solubility of $\mathrm{Sb}$ in a $\mathrm{GaN}$ solid. As a result, $\mathrm{Sb}$ may tend to segregate to the growth surface and result in changes in GaN surface properties, thereby acting as a surfactant. Therefore, we believe that the observation of enhanced lateral growth rate as well as the formation of vertical facets over a range of temperatures result from changes in the surface processes induced by the addition of $\mathrm{Sb}$.

$\mathrm{Sb}$ addition to the growth environment must affect specific surface processes operant during growth. Since $\mathrm{Sb}$ is not incorporated into the growing film, it is reasonable to assume the presence of a high surface concentration of $\mathrm{Sb}$ can affect the fundamental surface processes during growth. These processes of adsorption/desorption, diffusion and incorporation are strongly affected by the atomic level surface Downloaded 07 Mar 2007 to 128.104.198.190. Redistribution subject

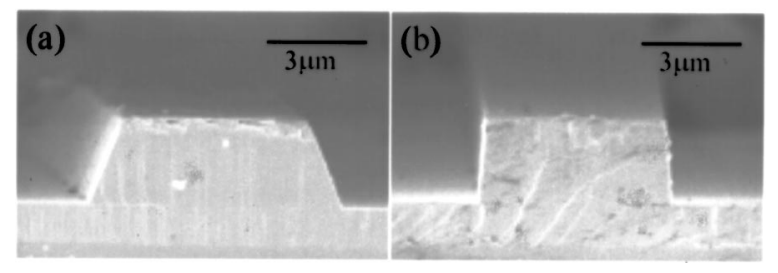

FIG. 2. Cross-sectional SEM images of undoped (a) and Sb-doped (b) LEO islands grown at $1075^{\circ} \mathrm{C}$. The $\mathrm{Sb} / \mathrm{Ga}$ mole ratio is $6 \%$ in the gas phase.

structure and chemistry. The change in facet structure seen in the Sb-based LEO structure is analogous to the growth of non-Sb-doped materials at a lower V/III ratio. ${ }^{14}$ The formation of vertical facets, typically seen at high temperatures and low V/III ratios, is seen in the Sb-based LEO case over a wide range of growth conditions. Vertical facets are favored under conditions that should lead to a lower N-to-Ga ratio on the surface. Such conditions favor enhanced Ga surface diffusion, ${ }^{15}$ which may be, along with specific surface energy considerations, the driving force for the appearance of the $\{11 \overline{2} 0\}$ vertical facets. A reasonable assumption is that the presence of $\mathrm{Sb}$ on the surface enhances the desorption or impedes the surface decomposition of $\mathrm{NH}_{3}$, and/or enhances the surface diffusion of $\mathrm{Ga}$ adatoms. In both cases, the $\mathrm{Sb}$ on the surface would lead to local conditions that are analogous to a lower input V/III ratio. As in all cases of surface effects in the chemical vapor deposition, specific surface reactions are difficult to experimentally ascertain and further detailed work is required to obtain both a model of GaN growth as well as the influence of $\mathrm{Sb}$ on these processes.

In summary, a small addition of $\mathrm{Sb}$ was found to have a remarkable effect on the facet formation and growth rates of GaN growth during the LEO process by MOVPE. We attribute the increase in lateral overgrowth rate to $\mathrm{Sb}$ acting as a surfactant during GaN growth.

The authors thank the DARPA-EPRI program on power electronics and ONR MURI on compliant substrates (C. Wood) for funding of the research. Facilities support by the NSF University of Wisconsin-Materials Research Science and Engineering Center is gratefully acknowledged.

${ }^{1}$ M. Copel, M. C. Reuter, E. Kaxiras, and R. M. Tromp, Phys. Rev. Lett. 63, 632 (1989).

${ }^{2}$ M. Copel, M. C. Reuter, M. Horn von Hoegen, and R. M. Tromp, Phys. Rev. B 42, 11682 (1990).

${ }^{3}$ J. Massies, N. Grandjean, and V. H. Etgens, Appl. Phys. Lett. 61, 99 (1992).

${ }^{4}$ D. Kandel and E. Kaxiras, Phys. Rev. Lett. 75, 2742 (1995).

${ }^{5}$ I. Markov, Phys. Rev. B 53, 4148 (1996).

${ }^{6}$ R. T. Lee, J. K. Shurtleff, C. M. Fetzer, G. B. Stringfellow, S. M. Lee, and T. Y. Seong, J. Appl. Phys. 87, 3730 (2000).

${ }^{7}$ S. Nakamura, M. Senoh, S. Nagahama, N. Iwase, T. Yamada, T. Matsushita, H. Kiyoku, Y. Sugimoto, T. Kozaki, H. Umemoto, M. Sano, and K. Chocho, Appl. Phys. Lett. 72, 211 (1998).

${ }^{8}$ P. Fini, L. Zhao, B. Moran, M. Hansen, H. Marchand, J. P. Ibbetson, S. P. DenBaars, U. K. Mishra, and J. S. Speck, Appl. Phys. Lett. 75, 1706 (1999).

${ }^{9}$ O. H. Nam, T. S. Zheleva, M. D. Bremser, and R. F. Davis, J. Electron. Mater. 27, 233 (1998).

${ }^{10}$ K. Hiramatsu, H. Matsushima, T. Shibata, N. Sawaki, K. Tadatomo, H. Okagawa, Y. Ohuchi, Y. Hondo, and T. Matsue, Mater. Res. Soc. Symp. Proc. 482, 257 (1998).

${ }^{11}$ K. Yamaguchi and K. Okamoto, Jpn. J. Appl. Phys., Part 1 32, 1523 (1993).

AlP license or copyright, see http://apl.aip.org/apl/copyright.jsp 
${ }^{12}$ H. Marchand, J. P. Ibbetson, P. T. Fini, S. Keller, S. P. DenBaars, J. S. Speck, and U. K. Mishra, J. Cryst. Growth 195, 328 (1998).

${ }^{13}$ B. Beaumont, S. Haffouz, and P. Gibart, Appl. Phys. Lett. 72, 921 (1998).

${ }^{14}$ R. Zhang, L. Zhang, D. M. Hansen, M. P. Boleslawski, K. L. Chen, D. Q.
Lu, B. Shen, Y. D. Zheng, and T. F. Kuech, MRS Internet J. Nitride Semicond. Res. 4S1, G4.7 (1999).

${ }^{15}$ T. K. Zywietz, J. Neugebauer, and M. Scheffler, Appl. Phys. Lett. 73, 487 (1998). 